\title{
ARTHROSCOPIC SURGERY IN CHILDREN AND ADOLESCENT - A DOMAIN TO BE DEVELOPED
}

\author{
Ștefana Carp ${ }^{1}$, Laura Popa ${ }^{1}$, Eduard Liciu ${ }^{1}$, Camelia Vreme ${ }^{2}$, Costel Vlad ${ }^{1}$
}

\begin{abstract}
The application of arthroscopic surgery in children is becoming wider and a more complete understanding of its use is needed.

In this article we present our experience with arthroscopic surgery over the course of 17 months, from April 2019 until October 2020.

We diagnosed and treated minimally invasive 49 patients, with ages between 6 and 18 years old, 22 boys $(44.9 \%)$ and 27 girls (55.1\%). The pathologies varied, the most common being anterior cruciate ligament tears with 49 cases representing $49 \%$, some of which also needed meniscal repair with sutures or by partial meniscectomies. Second most common condition was isolated meniscal tears in 8 patients representing $16.33 \%$ of all cases.

But the application of arthroscopic approach is not limited to the treatment of knee instability or related sports injuries. We also want to emphasize the importance of a minimal invasive treatment when it comes to lose bodies in the elbow by presenting a case of an incarcerated medial humeral epicondyle after an elbow dislocation, a case of a symptomatic os trigonum in a 14 years old swimmer or a fractured anterior calcaneal process unresponsive to the conservative treatment, tibial spine fracture in a six years old child.
\end{abstract}

The benefits of minimally invasive surgery are widely accepted among the orthopaedic surgeons, but it is yet under a lot of reluctance in the paediatric professionals because of the sometimes slow and difficult learning curve.

Keywords: arthroscopy, children, anterior cruciate ligament, epicondyle fracture, os trigonum

\section{Introduction}

Since the late 50's when arthroscopy was invented by Watanabe et all [1] the advantages of minimally invasive surgery increasingly has led to the expansion of arthroscopic procedure in adults and later in children. As many other devices, the arthroscopy tools and procedures needed to be adapted to childhood conditions and to the slower learning curves in paediatric field of orthopaedic surgery.
Virtually, all joints may be approached arthroscopically [2-4], ankle, knee, hip, elbow, shoulder, many excisional, reparative or reconstructive gestures being possible via small portals.

Unfortunately, the expansion of arthroscopic techniques in children encounters the same economic and cultural obstacles as any other new technique.

The purpose of this paper is to report our experience with the arthroscopic techniques in children.

\section{Materials and Methods}

Between April 2019 and October 2020, we used arthroscopic techniques in different paediatric conditions. Most of our arthroscopic procedures addressed the adolescent knee to reconstruct anterior cruciate ligament (ACL) or repair the menisci. Besides, some uncommon conditions were approached arthroscopically: anterior calcaneal process pseudarthrosis, removal of os trigonum, tibial eminence fracture in small child, removal of incarcerated medial epicondyle of humerus.

All cases of arthroscopic procedures in our department were identified and the data were collected afterward. The patients' charts were reviewed, the main characteristic of patients is centralised in Table 1: sex, age, type of surgery, achievement of full recovery, complications and follow-up.

\section{Results}

We performed arthroscopic surgery in 49 patients, with ages between 6 and 18 years old, with various pathologies. Of the 49 patients 22 were boys $(44.9 \%)$ and 27 were girls (55.1\%). There were 25 patients $(49 \%)$ who required ACL repair, of which $3(12 \%)$ also had meniscal sutures and 5 $(20 \%)$ had partial meniscectomies. Of the 25 patients, 13 $(52 \%)$ were boys and 12 girls (48\%).

Another $8(16.33 \%)$ patients had meniscal tears that required meniscal sutures, and $9(18.37 \%)$ patients were treated by partial meniscectomy. Of these 17 patients, two girls, ages 8 and 13 were diagnosed with discoid meniscus.

The median age of patients who needed knee arthroscopy for ACL tear or meniscal repair was 15 years.

${ }^{1}$ Paediatric Orthopaedic Department, Clinical Hospital for Children Dr. Victor Gomoiu

${ }^{2}$ Paediatric Orthopaedic Department, Emergency Hospital for Children MS Curie

E-mail: stefana.carp@gmail.com, 1.lauradobre@gmail.com, liciueduard@gmail.com, camelia1990_camelia1990@yahoo.com, costelvlad.cv@gmail.com 
Table 1: Main characteristics of study group.

\begin{tabular}{|c|c|c|c|c|c|c|c|}
\hline Patient & Sex & $\begin{array}{l}\text { Age } \\
\text { (years) }\end{array}$ & Surgery & Joint & $\begin{array}{l}\text { Complete } \\
\text { recovery } \\
\text { achieved }\end{array}$ & Remarks & $\begin{array}{l}\text { Follow up } \\
\text { (months) }\end{array}$ \\
\hline 1 & $\mathrm{~F}$ & 12 & Meniscectomy & Right Knee & yes & & 20 \\
\hline 2 & $\mathrm{~F}$ & 16 & Meniscectomy & Right Knee & yes & & 20 \\
\hline 3 & M & 16 & $\begin{array}{l}\mathrm{ACL} \text { reconstruction }+ \\
\text { meniscectomy }\end{array}$ & Left Knee & yes & & 19 \\
\hline 4 & $\mathrm{~F}$ & 14 & $\mathrm{ACL}$ reconstruction & Left Knee & yes & & 18 \\
\hline 5 & $M$ & 17 & $\mathrm{ACL}$ reconstruction & Left Knee & yes & & 17 \\
\hline 6 & M & 13 & $\begin{array}{l}\mathrm{ACL} \text { reconstruction }+ \\
\text { meniscectomy }\end{array}$ & Right Knee & yes & & 17 \\
\hline 7 & $M$ & 15 & $\mathrm{ACL}$ reconstruction & Right Knee & yes & & 17 \\
\hline 8 & M & 11 & Tibial eminence fixation & Right Knee & yes & & 4 \\
\hline 9 & $\mathrm{~F}$ & 13 & Meniscectomy & Left Knee & yes & & 16 \\
\hline 10 & M & 17 & $\mathrm{ACL}$ reconstruction & Right Knee & no & Graft rupture & 13 \\
\hline 11 & $\mathrm{~F}$ & 12 & Meniscectomy & Right Knee & yes & & 13 \\
\hline 12 & $\mathrm{~F}$ & 14 & $\begin{array}{l}\mathrm{ACL} \text { reconstruction }+ \\
\text { meniscectomy }\end{array}$ & Left Knee & yes & & 13 \\
\hline 13 & $M$ & 18 & PCL reconstruction & Right Knee & yes & & 12 \\
\hline 14 & M & 17 & $\begin{array}{l}\mathrm{ACL} \text { reconstruction }+ \\
\text { meniscal suture }\end{array}$ & Left Knee & yes & & 12 \\
\hline 15 & $M$ & 16 & Meniscal suture & Right Knee & yes & & 12 \\
\hline 16 & $\mathrm{~F}$ & 15 & ACL reconstruction & Left Knee & yes & & 11 \\
\hline 17 & $\mathrm{~F}$ & 15 & ACL reconstruction & Right Knee & yes & & 11 \\
\hline 18 & M & 11 & Meniscectomy & Right Knee & yes & & 11 \\
\hline 19 & M & 16 & Meniscectomy & Right Knee & yes & & 11 \\
\hline 20 & M & 15 & Meniscectomy & Left Knee & yes & & 11 \\
\hline 21 & $M$ & 16 & $\mathrm{ACL}$ reconstruction & Left Knee & yes & & 10 \\
\hline 22 & $\mathrm{~F}$ & 6 & Tibial eminence fixation & Left Knee & no & $\begin{array}{l}\text { Incomplete } \\
\text { range of } \\
\text { motion }\end{array}$ & 11 \\
\hline 23 & $\mathrm{~F}$ & 12 & Meniscal suture & Left Knee & yes & & 10 \\
\hline 24 & $\mathrm{~F}$ & 12 & Meniscal suture & Left Knee & yes & & 10 \\
\hline 25 & $M$ & 16 & Loose body extraction & Right Knee & yes & & 10 \\
\hline 26 & $\mathrm{~F}$ & 17 & $\mathrm{ACL}$ reconstruction & Right Knee & no & $\begin{array}{l}\text { Incomplete } \\
\text { range of } \\
\text { motion }\end{array}$ & 10 \\
\hline 27 & $\mathrm{~F}$ & 16 & $\mathrm{ACL}$ reconstruction & Left Knee & yes & & 10 \\
\hline 28 & $\mathrm{~F}$ & 14 & Meniscal suture & Left Knee & yes & & 10 \\
\hline 29 & $M$ & 17 & ACL reconstruction & Right Knee & yes & & 10 \\
\hline 30 & $\mathrm{~F}$ & 14 & ACL reconstruction & Left Knee & yes & & 9 \\
\hline 31 & $\mathrm{~F}$ & 15 & $\begin{array}{l}\mathrm{ACL} \text { reconstruction }+ \\
\text { meniscal suture }\end{array}$ & Left Knee & yes & & 9 \\
\hline
\end{tabular}


JURNALUL PEDIATRULUI - Year XXIII, Vol. XXIII, Nr. 91-92, july-december 2020

\begin{tabular}{|c|c|c|c|c|c|c|c|}
\hline 32 & $\mathrm{~F}$ & 8 & Meniscal suture & Right Knee & yes & & 9 \\
\hline 33 & $\mathrm{~F}$ & 14 & Os trigonum resection & Left Ankle & yes & & 10 \\
\hline 34 & $M$ & 17 & Meniscal suture & Left Knee & yes & & 5 \\
\hline 35 & $\mathrm{~F}$ & 17 & $\mathrm{ACL}$ reconstruction & Right Knee & yes & & 5 \\
\hline 36 & $\mathrm{M}$ & 18 & $\begin{array}{l}\mathrm{ACL} \text { reconstruction }+ \\
\text { meniscal suture }\end{array}$ & Left Knee & yes & & 5 \\
\hline 37 & $M$ & 17 & $\begin{array}{l}\mathrm{ACL} \text { reconstruction }+ \\
\text { meniscectomy }\end{array}$ & Left Knee & yes & & 5 \\
\hline 38 & $\mathrm{M}$ & 17 & $\mathrm{ACL}$ reconstruction & Right Knee & yes & & 5 \\
\hline 39 & $\mathrm{~F}$ & 14 & $\begin{array}{l}\text { Anterior calcaneal process } \\
\text { resection }\end{array}$ & Left Ankle & yes & & 4 \\
\hline 40 & $\mathrm{M}$ & 15 & $\mathrm{ACL}$ reconstruction & Right Knee & yes & & 3 \\
\hline 41 & $\mathrm{~F}$ & 14 & Meniscal suture & Left Knee & yes & & 3 \\
\hline 42 & $\mathrm{~F}$ & 16 & $\mathrm{ACL}$ reconstruction & Left Knee & yes & & 3 \\
\hline 43 & $\mathrm{~F}$ & 16 & ACL reconstruction & Left Knee & yes & & 3 \\
\hline 44 & $\mathrm{~F}$ & 17 & Meniscal suture & Left Knee & yes & & 2 \\
\hline 45 & $\mathrm{M}$ & 17 & $\begin{array}{l}\mathrm{ACL} \text { reconstruction }+ \\
\text { meniscectomy }\end{array}$ & Left Knee & no & & 1 \\
\hline 46 & $\mathrm{~F}$ & 17 & Meniscectomy & Right Knee & no & & 1 \\
\hline 47 & $\mathrm{M}$ & 11 & Loose body extraction & Left Elbow & no & $\begin{array}{l}\text { Incomplete } \\
\text { range of } \\
\text { motion }\end{array}$ & 1 \\
\hline 48 & $\mathrm{~F}$ & 14 & Meniscectomy & Right Knee & no & & 1 \\
\hline 49 & $\mathrm{~F}$ & 13 & ACL reconstruction & Left Knee & no & & 1 \\
\hline
\end{tabular}

Other pathologies which needed arthroscopic intervention were: knee arthroscopy for tibial spine fractures ( 2 patients) and for a posterior cruciate ligament rupture (1 patient), ankle arthroscopy for anterior calcaneal process fracture ( 1 patient) and for a symptomatic os trigonum (1 patient), elbow arthroscopy for an incarcerated medial humerus epicondyle ( 1 patient). We also had a case of a 16-year-old boy with multiple intraarticular loose bodies after lateral femoral condyle osteochondritis dissecans.

Time of full recovery varies on the pain threshold of each patient, but it is expected that in 6 to 8 weeks, full range of motion is acquired. In the ACL reconstruction group, we had two patients (8\%) who didn't achieve full recovery, a girl because of a failure to maintain the recovery program, and a boy who suffered a graft rupture at 3 months after surgery.

The recovery of full range of motion can be more problematic when it comes to intraarticular fracture, even the ones treated minimally invasive. To this idea we have the example of a tibial spine fracture on a 6 years old girl, currently at 11 months after surgery, and an incarcerated medial epicondyle humerus fracture on a 11 years old boy, at 2 months after surgery, who have yet to achieve full range of motion.

\section{Anterior cruciate ligament reconstruction}

All surgeries were performed under pneumatic tourniquet assistance, the patient being positioned in decubitus with knee flexed at 90 degrees and hip flexed so the foot and buttock are on the same level (Figure 1.A). The technique we use in our department is based on principle of anatomical single bundle reconstruction of ACL. The autograft source was semitendinosus and gracillis tendons (Figure 1.B). The tunnels were transphyseal in all cases (Figure 1.C,D ). The fixation in the femoral tunnel is made with adjustable loop and the fixation in the tibial tunnel is achieved with interference screw. The placement of tunnels is based on principle of respect of native ligaments footprints. On occasions we preferred to verify the tunnel placement with fluoroscopy according to lateral X-ray criteria of tunnel placement [5].

Suction drainage was placed in all cases and removed at 24-48 hours after surgery. The knee was immobilised in 15 degrees of flexion with an adjustable hinged knee brace. The patient was mobilised early after surgery with contact of the foot with the ground but no load for 3 weeks. The load is started after the $3^{\text {rd }}$ week and progressively completed to the $6^{\text {th }}$ week post-surgery. In all this time the passive and active recovery of the knee flexion is worked. The recovery protocol is started during the hospital stay and continued after discharging. 

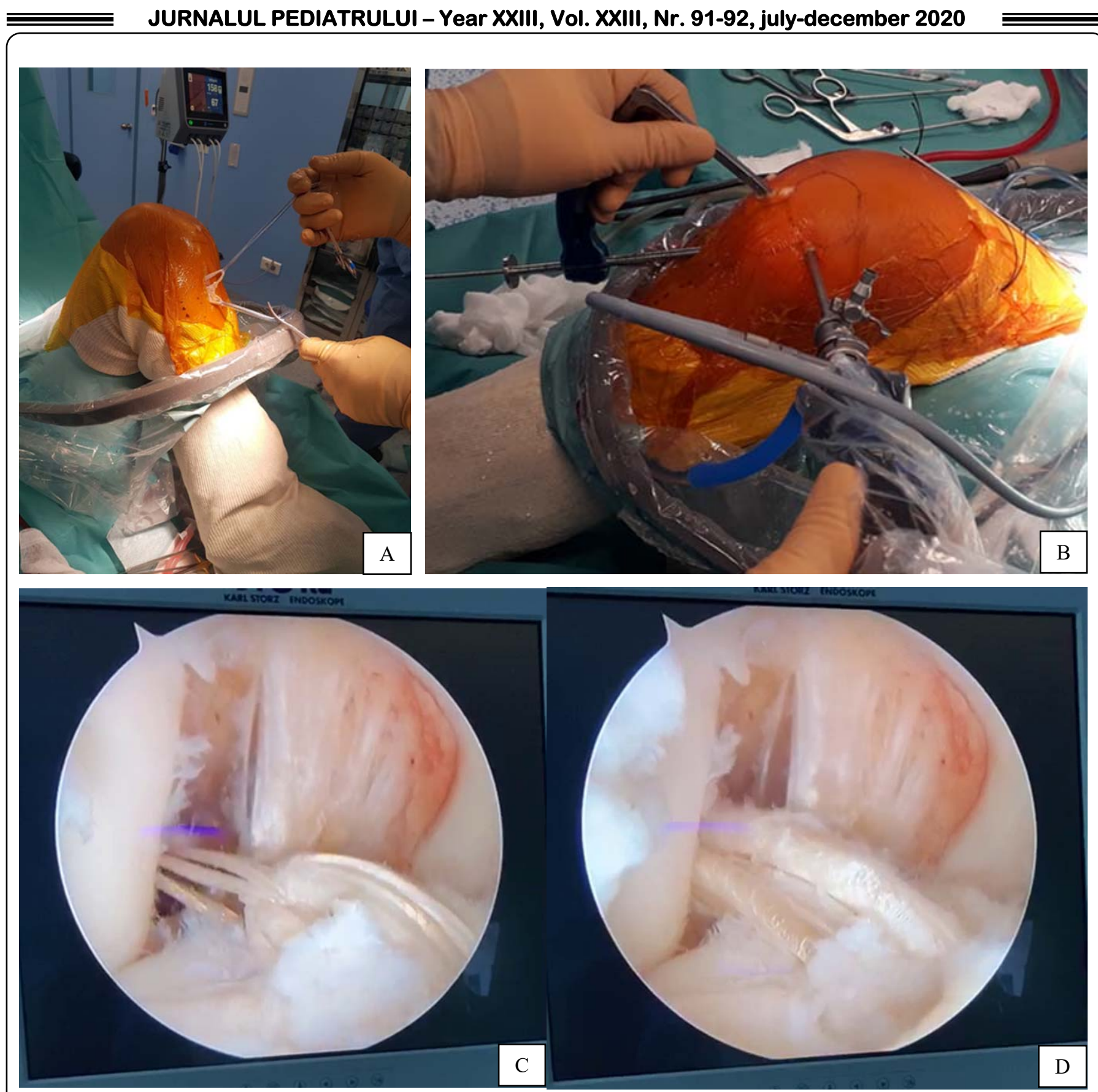

Figure 1. A - Semitendinous and gracillis tendon dissection. B - The tibial tunnel is made transphyseal. C Intraoperative image of the right femoral notch, the graft is about to enter the joint and travel (upward and laterally) to the lateral femoral condyle, pulled by the adjustable loop. D - Intraoperative image of the right femoral notch, the graft is in place.

In some cases, the recovery treatment was assisted remotely via smart devices providing learning tools for the patient to execute passive flexion-extension of the knee with settings of time and speed that allow calibration according to the individual needs and pain threshold.

In 3 patients the ACL reconstruction was accompanied by the meniscus repair and in 5 patients the ACL reconstruction was accompanied by meniscus partial resection.
Even though complete range of motion was accomplished in one case, unadvised sport activity resulted in a graft complete tear at 3 months after arthroscopic repair. In one case the recovery protocol was not properly followed so at 10 months post-surgery the lack of 5 degrees of full extension is to be recovered.

In one case a discrete snap during knee flexion persisted for 8 months after surgery. The subjective "giving way" or "giving out" sensation of the knee disappeared in all cases. 


\section{Os trigonum resection}

A 14 year old girl, swimmer, presenting with posterior ankle impingement was operated because of important function impairment during walk and run. X-ray exam (Figure 2.A) and CT (Figure 2.B) exam were performed prior to surgery. The patient was placed in prone position. Two portals adjacent to the Achilles tendon were used. The work chamber was created prior to portals creation by injecting saline solution in the ankle. The os trigonum was identified and harvested with a motorized burr. The flexor hallucis longus was exposed during surgery. The resection was complete and the recovery was fast (Figure 2.C,D). At 48 hours after surgery the patient was able to walk on heals and on tiptoes without any pain. Very discrete hemarthrosis was present.
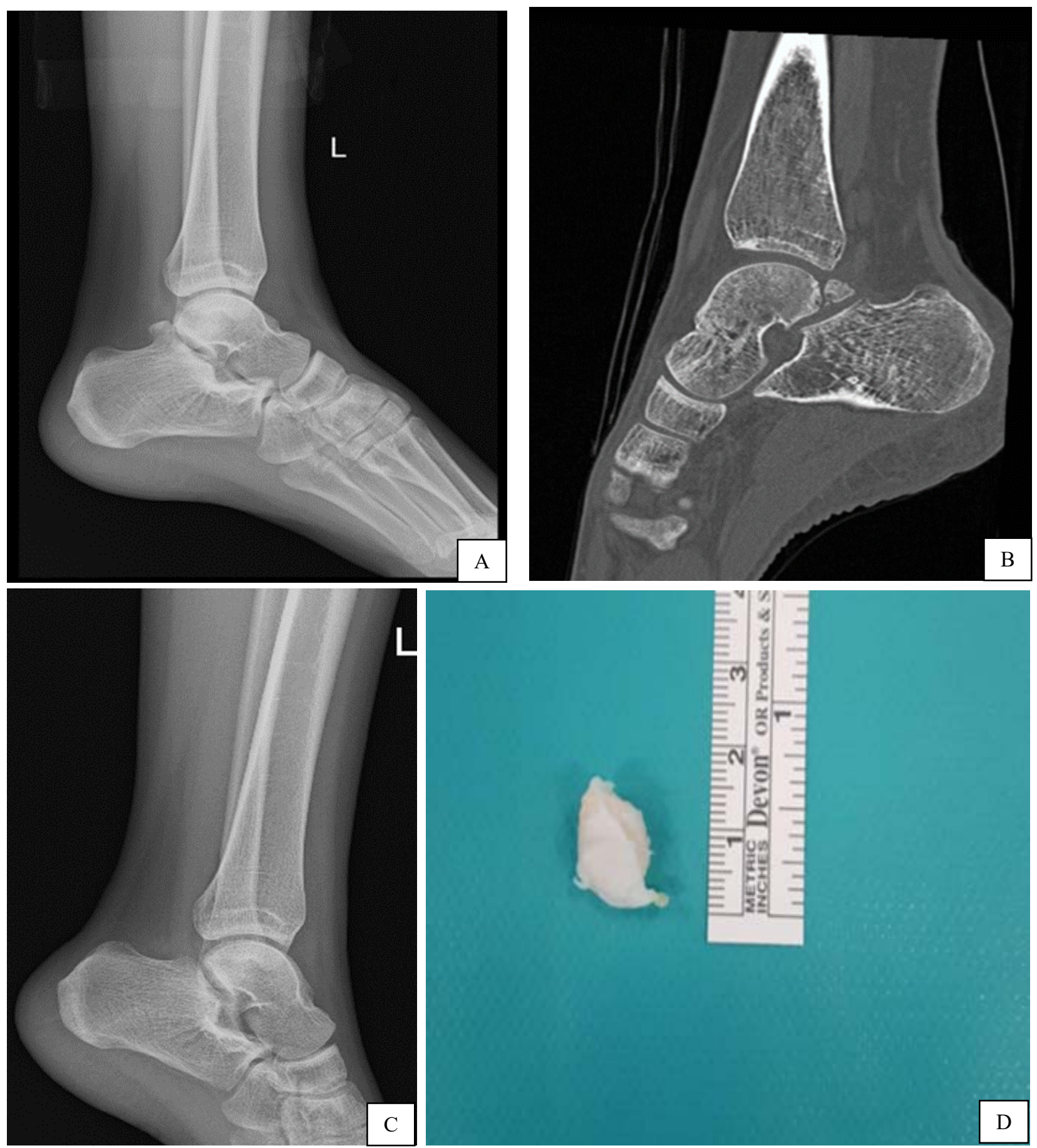

Figure 2. A - Lateral view of the ankle on the X-ray demonstrating the presence of os trigonum. B - Figure 2.b: CT scan examination of os trigonum. C - Postoperative X-ray of the ankle, showing good resection of os trigonum. D - The osteocartilaginous fragment removed from the ankle joint. 


\section{Anterior calcaneal process pseudarthrosis}

A 14 years old girl presented in our department with chronic pain of the midfoot, without known history of trauma. The pain was provoked by medium walking, 5001000 meters, since few months. Clinical examination revealed fixed pain corresponding to a point 2 centimetres in front of the sinus tarsi. The subtalar joint mobilisation and the attempt to mobilise the Chopart joint triggered the pain corresponding to anterior calcaneal process. The X-ray (Figure 3. A) and CT (Figure 3. B,C) scan revealed a small bony fragment seeming to be avulsed from the anterior calcaneal process. We described this as an old fracture with no signs of healing. An immobilisation with short leg cast was recommended. After 6 weeks of immobilisation no signs of healing process or symptoms improvement were identified and we recommended the arthroscopic removal of the avulsed fragment. The operation was performed arthroscopically under fluoroscopy (Figure 3. D,E). The avulsed fragment was removed with a burr. The recovery process was started immediately after surgery. Full weight bearing of operated foot was authorized 3 weeks after surgery with no pain. The tolerance to long distance walks returned to normal.
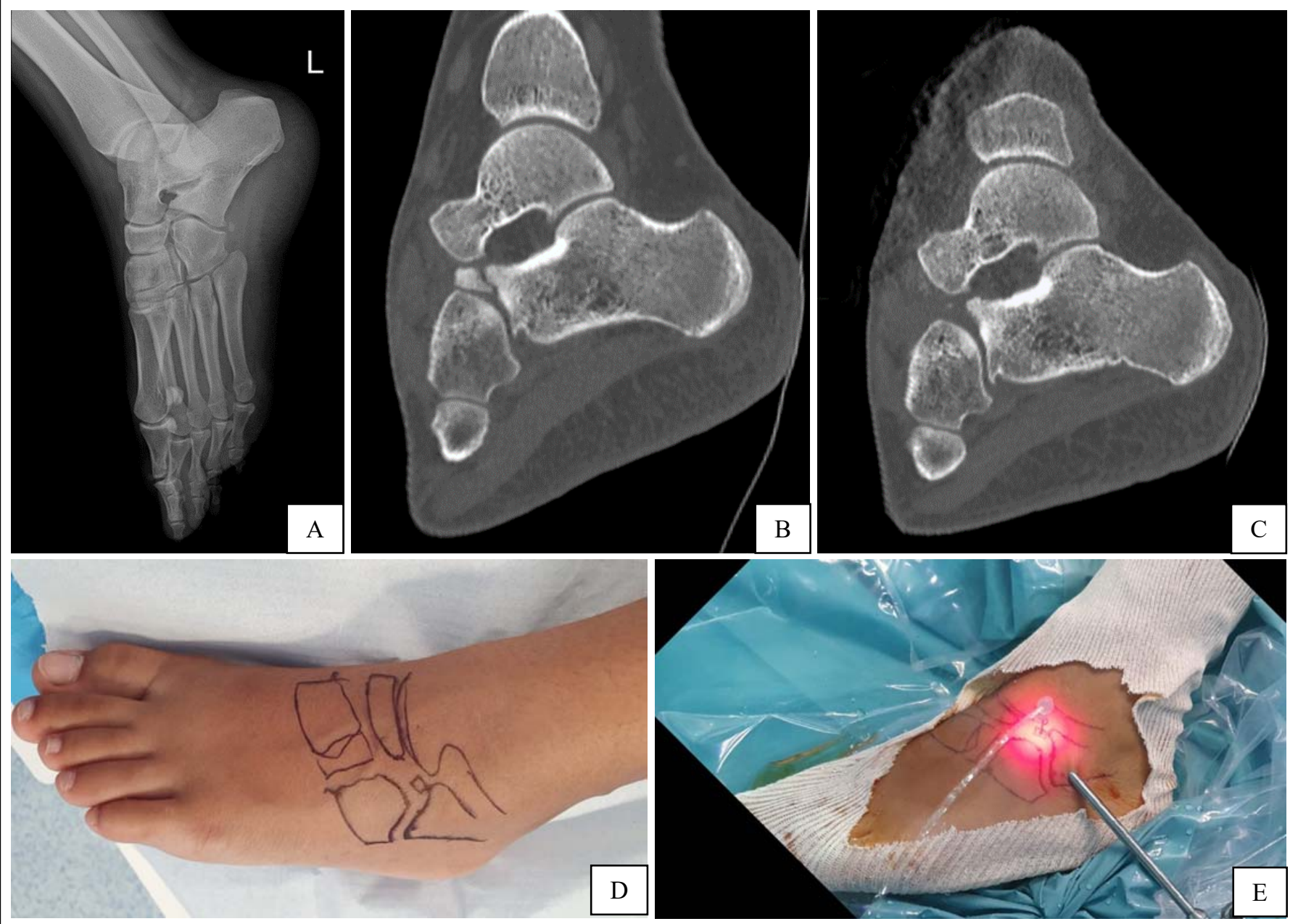

Figure 3. A - Anterior calcanean process is fractured, visible at X-ray exam. B - Preoperative CT scan demonstrating the fracture of anterior calcaneal process. C - Postoperative CT scan examination, the intraarticular fragment was completely removed. D - Intraoperative landmarks identified under fluoroscopy. E - Intraoperative aspect of portal placement to remove the anterior calcaneal process.

\section{Tibial spine fracture}

A 6 years old girl was referred to our service one week after a fall from toboggan, presenting a type IV Meyers and McKeever tibial spine fracture (Figure 4. A). An arthroscopic assisted transphyseal fixation with nonabsorbable suture and anterior button was performed. Intraoperative exploration revealed the anterior horn of medial meniscus incarcerated. The fixation material was removed 3 months after the surgery. The recovery has begun 3 weeks after surgery and was disrupted due to pandemics rush. The flexion recovered slowly, at 10 months after surgery 20 degrees of flexion is to be recovered. Postoperative CT showed good integration of avulsed bony fragment (Figure 4. B). 

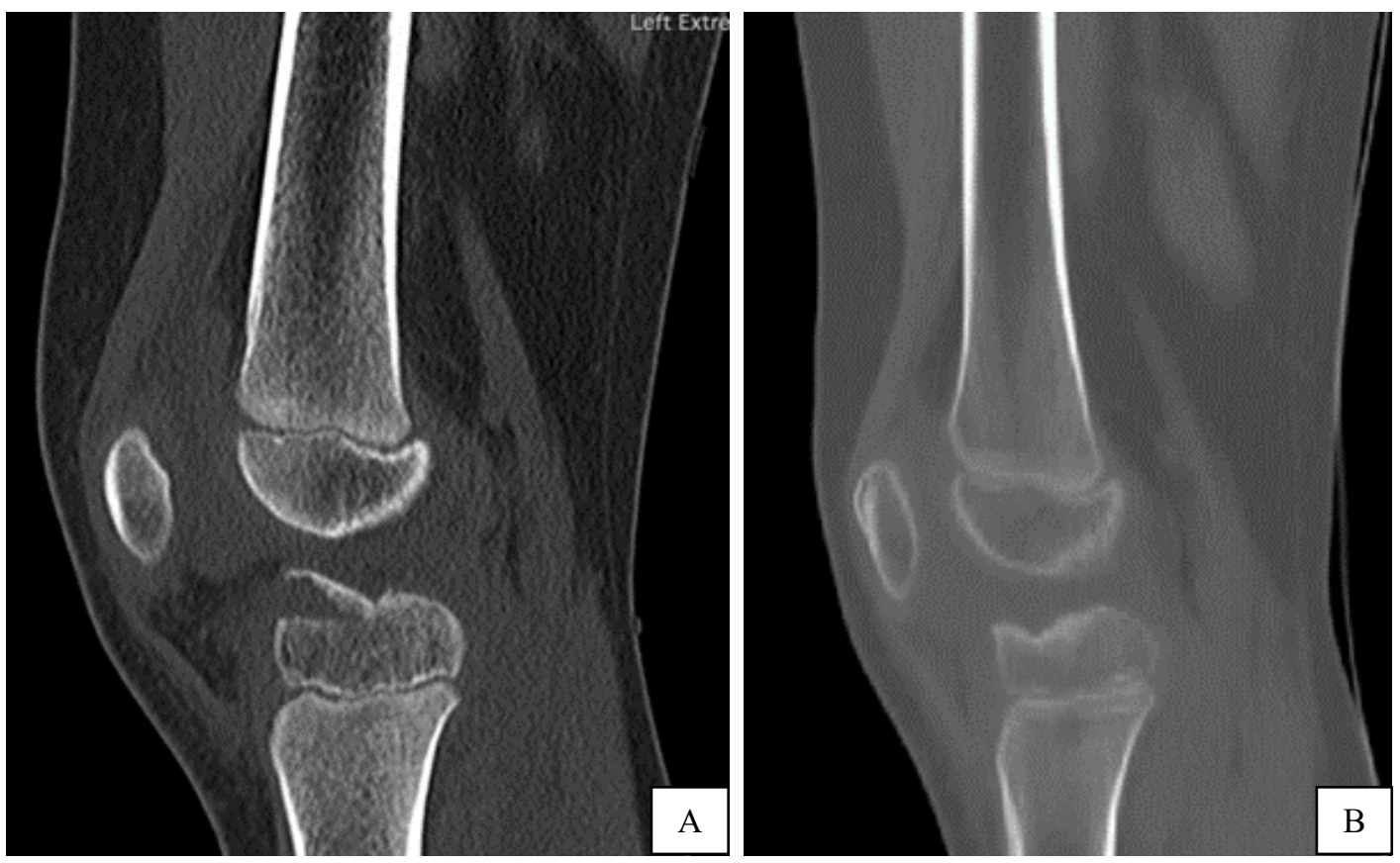

Figure 4. A Preoperative CT scan demonstrating displaced tibial spine fracture in 6 years old girl. B - Postoperative CT scan at 6 months follow-up demonstrating good integration of avulsed fragment.

\section{Humerus medial epicondyle removal}

An 11 years old boy presented in our department with fixed stiff elbow and a misdiagnosed fracture of medial epicondyle of left humerus, after 4 weeks of immobilisation because an elbow dislocation (Figure 5. A). The CT scan and MRI exam revealed the incarceration of an osteochondral fragment of the medial epicondyle into the humeroulnar joint. The removal of the fragment was performed arthroscopically via posteromedial and posterolateral portals (Figure 5. B). Intraoperatively we discovered a small defect in the olecranon articular surface; a reparation procedure was considered unnecessary (Figure 6. A,B). The stiffness changed rapidly postoperatively from fixed to elastic. The recovery is ongoing, the patient gained 90 degrees of mobility during the first month postoperatively. The elbow is stable and nonpainful.
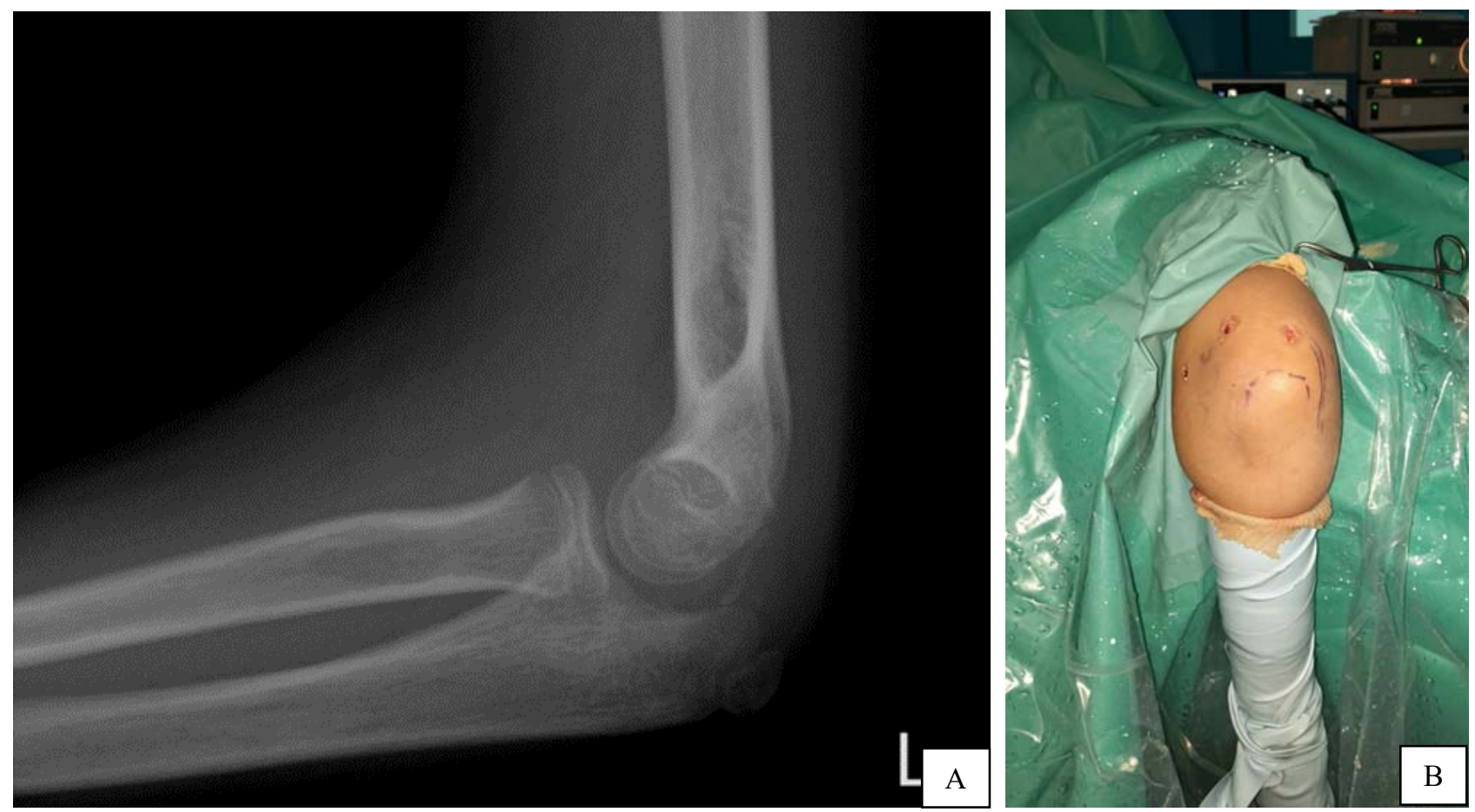

Figure 5. A - Humeroulnar subluxation secondary to incarceration of osteochondral medial epicondyle fragment. B - Portals placement for elbow arthroscopy. 


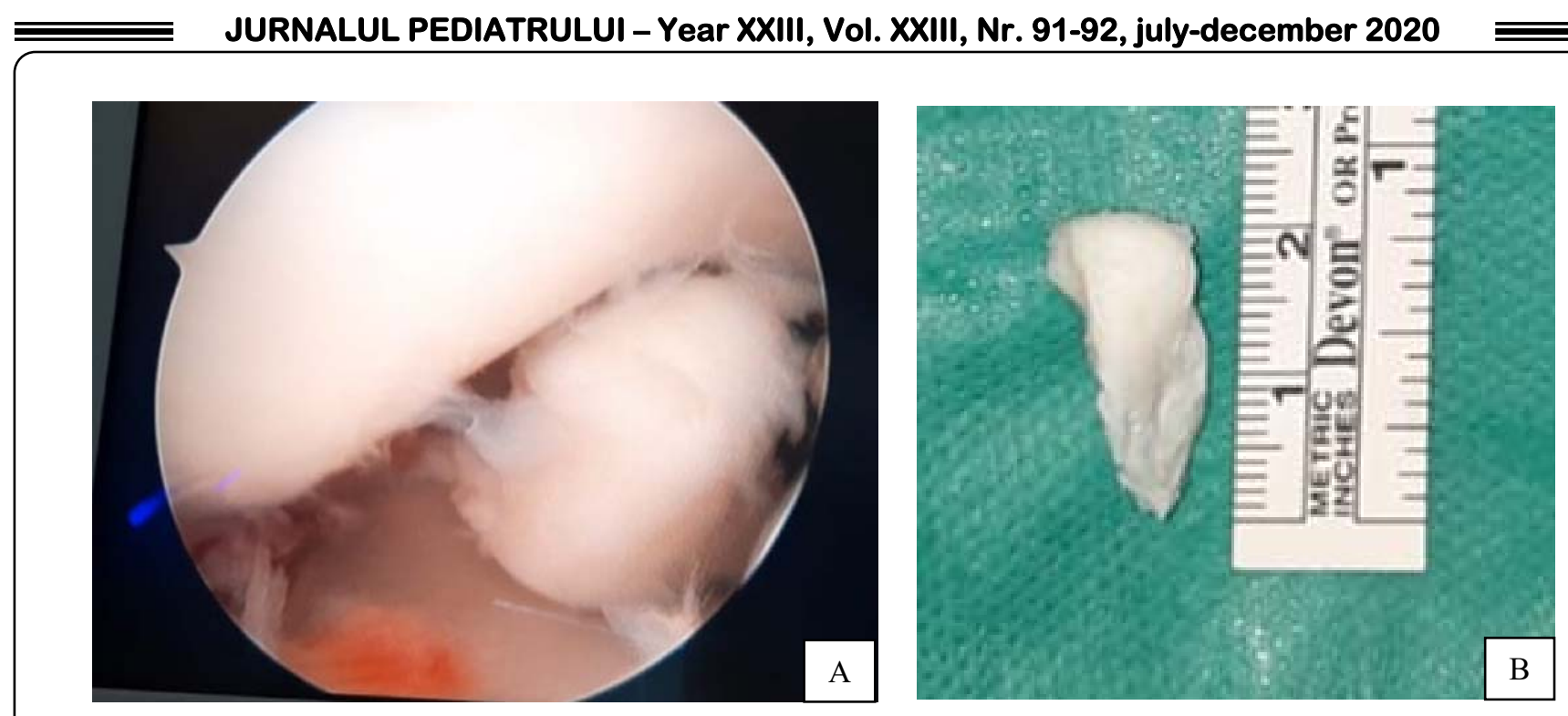

Figure 6. A - Intraoperative aspect demonstrating the large osteochondral fragment trapped between the humeral trochlea and olecranon. B - Osteochondral fragment removed from the elbow joint.

\section{Discussion}

ACL reconstruction in paediatric population was subject of debate. Few aspects of ACL tears diagnosis and treatment were the subject of international consensus [6].

Concerning the diagnosis there are two remarks to keep in mind. When the clinical exam does not reveal instability of the knee or the MRI exam is negative the probability of having an ACL injury is low; on the other hand, the positive clinical examination or MRI exam cannot rule in an ACL tear in all cases. However, the decision making should not rely on one single test or examination technique.

One of the concerns raised by the ACL reconstruction is the physeal injury during tunnel creation. The international consensus [6] agreed the transphyseal techniques may be used in paediatric patients with the condition of not to place rigid plugs (bone or screws) in the growth plate. The soft tissue occupying the tunnel is protective against the development of bony bridges and growth disturbances.

The moment to return to sport activities is another topic of debate. Two numbers should be emphasized. The duration of rehabilitation procedure should continue at least 9 months after the surgery. Returning to pivot activities should be delayed after $12^{\text {th }}$ months post-surgery [6] given high risk of re-rupture during the first 12 months after surgery.

Posterior ankle impingement syndrome is a recently entity approached with arthroscopic tools[7]. The condition is generated by the mechanical conflict in the rear ankle. Removal of os trigonum is reserved for people engaged in athletic activities or if the conservative treatment has failed. Despite the small space to work and the neighbourhood of the posterior tibial bundle the technique is reliable giving good access and even better visualisation than open technique. Yasui [7] described a four staged systematic arthroscopic approach to the posterior ankle. After a systematic inspection of the ankle the fragment is removed with a burr.
The technique we used in the treatment of anterior calcaneal process pain syndrome was inspired by the treatment of calcaneonavicular coalition [8]. However, the mechanism we illustrated in this case may be part of TLAP syndrome[9]. Given the fibrous attachment on the fragment we found during surgery a fracture secondary to fibrous calcaneonavicular coalition is highly probable. Few open or miniopen techniques are described to remove the calcaneonavicular coalition [10]. Arthroscopy is an attractive method given the minimisation of the articular instability of the midfoot joint secondary to surgical approach.

Displaced tibial eminence fracture in children is a rare condition requiring surgical treatment. The choosing of hardware fixation is limited by the presence of growth plate and the poor bone quality immediately below the avulsed fragment. Transphyseal techniques are attractive due to the strength generated by the new nonabsorbable sutures [11]. We used a simplified technique and passed a suture behind the ACL, the loop was closed outside the bone, over a titanium button. The MRI showed an excellent reduction of the fracture. The slow progression of the rehabilitation pushed us to remove the implant three months after the surgery due to some skin discomfort in front of the titanium button. Arthrofibrosis is a known complication of the tibial spine fracture [12]. Early start of rehabilitation program may enhance the development of such complication. The quality of recovery is in direct relation to the quality of fixation, given the limitation of hardware volumes we can use in children, the suture fixation is a better option.

Medial epicondyle fracture in children may be easily misdiagnosed [13]. The incomplete ossification of the distal humerus at different stages of development make the diagnosis even more difficult. Advanced diagnosis tools as CT or MRI may be necessary to have a correct description of the fracture. Incarcerated medial epicondyle fracture needs early surgical treatment in order to avoid articular stiffness [14]. Elbow stiffness secondary to the elbow 
dislocation is an invalidating condition needing surgery [15] to restore the range of motion. Foreign body removal using arthroscopic tools is an attractive alternative allowing early start of rehabilitation. The case we presented in this paper is particular because of small amount of bone tissue in the avulsed fragment and difficulty of visualisation on X-ray exam and even at CT scan.

Patient comfort and duration of full recovery are indicators of quality of life after surgery. The pain is influencing considerably the recovery process, the level of pain is in direct relationship with the soft tissue damage during the surgery. Minimally invasive techniques are expected to generate less pain comparing with open surgery and consequently better quality of life after surgery. This domino effect may explain the amount of work to develop minimally invasive techniques. Given the techniques developed for small patient are based on lessons learned after the development in adult surgery a gap is appearing between the development of such techniques for paediatric patient when comparing with adults.

\section{References}

1. Accadbled F, N'Dele D: Arthroscopic Treatment of Pediatric Fractures. J Pediatr Orthop 2018, 38 Suppl 1:S29-S32.

2. Alt V, Gasnier J, Sicre G: Injuries of the scapholunate ligament in children. [Miscellaneous Article]: Journal of Pediatric Orthopaedics B September 2004;13(5):326329.

3. Memisoglu Ka, Muezzinoglu USa, Atmaca Hb, Sarman Hc, Kesemenli CCa: Arthroscopic fixation with intraarticular button for tibial intercondylar eminence fractures in skeletally immature patients. [Miscellaneous Article]: Journal of Pediatric Orthopaedics B January 2016;25(1):31-36.

4. Lee D-HMD, Jeong W-KMD, Lee S-HMDP: Arthroscopic Excision of Osteoid Osteomas of the Hip in Children. [Miscellaneous Article]: Journal of Pediatric Orthopaedics September 2009;29(6):547-551.

5. Parkar AP, Adriaensen ME, Strand T, Inderhaug E, Harlem T, Solheim E: How to read post-operative radiographs and $\mathrm{CT}$ scans after single-bundle anterior cruciate ligament reconstruction. Skeletal Radiol 2013, 42(11):1489-1500.

6. International Olympic Committee Pediatric ACLICG, Ardern CL, Ekas G, Grindem H, Moksnes H, Anderson AF, Chotel F, Cohen M, Forssblad M, Ganley TJ et al: 2018 International Olympic Committee Consensus Statement on Prevention, Diagnosis, and Management of Pediatric Anterior Cruciate Ligament Injuries. Orthop J Sports Med 2018, 6(3):2325967118759953.

7. Yasui Y, Hannon CP, Hurley E, Kennedy JG: Posterior ankle impingement syndrome: A systematic four-stage approach. World J Orthop 2016, 7(10):657-663.

8. Knörr J, Accadbled F, Abid A, Darodes P, Torres A, Cahuzac JP, Sales de Gauzy J: Arthroscopic treatment of calcaneonavicular coalition in children. Orthop Traumatol Surg Res 2011, 97(5):565-568.

9. [9] Guignand D, Journeau P, Mainard-Simard L, Popkov D, Haumont T, Lascombes P: Child calcaneonavicular coalitions: MRI diagnostic value in a 19-case series. Orthop Traumatol Surg Res 2011, 97(1):67-72.

10. Kothari A, Masquijo J: Surgical treatment of tarsal coalitions in children and adolescents. EFORT Open Rev 2020, 5(2):80-89.

11. Gamboa JT, Durrant BA, Pathare NP, Shin EC, Chen JL: Arthroscopic Reduction of Tibial Spine Avulsion: Suture Lever Reduction Technique. Arthrosc Tech 2017, 6(1):e121-e126.

12. Gans I, Babatunde OM, Ganley TJ: Hybrid fixation of tibial eminence fractures in skeletally immature patients. Arthrosc Tech 2013, 2(3):e237-242.

13. Fernandez FF, Vatlach S, Wirth T, Eberhardt O: Medial humeral condyle fracture in childhood: a rare but often overlooked injury. Eur J Trauma Emerg Surg 2019, 45(4):757-761.

14. Dodds SD, Flanagin BA, Bohl DD, DeLuca PA, Smith BG: Incarcerated medial epicondyle fracture following pediatric elbow dislocation: 11 cases. J Hand Surg Am 2014, 39(9):1739-1745.

15. Strauss NL, Lattanza L: Open surgical treatment of posttraumatic elbow contractures in children. Tech Hand Up Extrem Surg 2010, 14(2):108-113.

\section{Correspondence to:}

Costel VLAD,

Paediatric Orthopaedic Department,

Clinical Hospital for Children Dr. Victor Gomoiu,

Bd. Basarabia 21, Sector 2 Bucharest,

Tel. 0040314136700

E-mail: costelvlad.cv@gmail.com 